\title{
The omega-3 fatty acid content of krill protein concentrate influences bioavailability, tissue deposition, peroxidation, and metabolism in young rats
}

\author{
Kayla Marie Bridges \\ West Virginia University
}

Follow this and additional works at: https://researchrepository.wvu.edu/etd

\section{Recommended Citation}

Bridges, Kayla Marie, "The omega-3 fatty acid content of krill protein concentrate influences bioavailability, tissue deposition, peroxidation, and metabolism in young rats" (2009). Graduate Theses, Dissertations, and Problem Reports. 4443.

https://researchrepository.wvu.edu/etd/4443

This Thesis is protected by copyright and/or related rights. It has been brought to you by the The Research Repository @WVU with permission from the rights-holder(s). You are free to use this Thesis in any way that is permitted by the copyright and related rights legislation that applies to your use. For other uses you must obtain permission from the rights-holder(s) directly, unless additional rights are indicated by a Creative Commons license in the record and/ or on the work itself. This Thesis has been accepted for inclusion in WVU Graduate Theses, Dissertations, and Problem Reports collection by an authorized administrator of The Research Repository @ WVU. For more information, please contact researchrepository@mail.wvu.edu. 


\title{
The Omega-3 Fatty Acid Content of Krill Protein Concentrate Influences Bioavailability, Tissue Deposition, Peroxidation, and Metabolism in Young Rats
}

\author{
Kayla Marie Bridges \\ Thesis submitted to the \\ Davis College of Agriculture, Forestry, and Consumer Sciences \\ at West Virginia University \\ in partial fulfillment of the requirements \\ for the degree of \\ Master of Science \\ in \\ Human Nutrition
Janet C. Tou, Ph.D., Chair Jacek Jaczynski, Ph.D.
Cindy Fitch, Ph.D., R.D. \\ Division of Animal and Nutritional Sciences \\ Morgantown, West Virginia \\ 2009
}

Keywords: Krill protein concentrate; eicosanoid; bioavailability; lipid oxidation; polyunsaturated fatty acids 


\section{ABSTRACT \\ The Omega-3 Fatty Acid Content of Krill Protein Concentrate Influences Bioavailability, Tissue Deposition, Peroxidation, and Metabolism in Young Rats}

\section{Kayla Marie Bridges}

Objective: Krill protein concentrate (KPC) has been determined to be a high quality protein for human consumption with the advantage of being a rich source of the omega-3 polyunsaturated fatty acids ( $\omega-3$ PUFAs), docosahexaenoic acid (DHA) and eicosapentaenoic acid (EPA). The $\omega-3$ PUFAs in krill are mainly associated with phospholipids, which have been proposed to result in high incorporation of $\omega-3$ PUFAs into tissues and to be stable against oxidation. The study objective was to determine bioavailability, tissue deposition, peroxidation, and metabolism of $\omega-3$ PUFAs in rats fed KPC.

Methods: Young female Sprague-Dawley rats ( $\mathrm{n}=10$ /group) were fed ad libitum isocaloric diets with either $10 \%$ freeze-dried KPC containing $0.9 \%$ krill oil with $4.4 \%$ corn oil $(\mathrm{KO}+\mathrm{CO})$ or $10 \%$ casein with $5.3 \%$ corn oil $(\mathrm{C}+\mathrm{CO})$ for 4 weeks. Bioavailability was measured by determining apparent digestibility of dietary lipid during the final week of the study. Fatty acid compositions of diets, various tissues, and feces were analyzed by gas chromatography. Lipid peroxidation was determined by TBARS. Total antioxidant capacity and urinary eicosanoid metabolites were determined by enzyme immunoassay.

Results: Rats fed $\mathrm{KO}+\mathrm{CO}$ had a low apparent digestibility (\%) of AA (22.75 \pm 6.45$)$, moderate apparent digestibility (\%) of EPA (70.12 \pm 3.52$)$ and high apparent digestibility $(\%)$ of DHA (93.42 \pm 1.64$)$. The $0.9 \% \mathrm{KO}$ from KPC increased $(P<0.01)$ EPA and DHA content in adipose and liver tissue while decreasing $(P<0.01)$ the $\omega-6$ PUFA, arachidonic acid. DHA was increased $(P=0.003)$ in the brain of rats fed $\mathrm{KO}+\mathrm{CO}$. There was no significant difference in total antioxidant capacity or lipid peroxidation between diets. Feeding the $\mathrm{KO}+\mathrm{CO}$ diet decreased $(P=0.009)$ urinary $\mathrm{PGE}_{2}$ metabolites. There was a tendency $(P=0.054)$ for decreased urinary 11-dehydro $\mathrm{TXB}_{2}$ in rats fed $\mathrm{KO}+\mathrm{CO}$.

Conclusion: The $0.9 \% \mathrm{KO}$ from KPC provided by the diet was able to increase $\omega-3$ PUFAs and decrease AA tissue accretion resulting in reduced pro-inflammatory eicosanoid metabolites. The results suggest that KPC from krill provides a healthy and sustainable alternative to fish or fish oil supplement. 


\section{ACKNOWLEDGEMENTS}

I would first like to thank my family and friends. I have two wonderful brothers, Daryl and Kyle, who always look out for my best interest. I would like to thank my parents, Al and Diane, for supporting and encouraging me through many difficult times; who have seen me at my worst and at my best. Without their perpetual support, I would have never made it to where I am today. I have amazing friends who have provided me with much support and words of wisdom. I would also like to thank God, for giving me the opportunity to use my knowledge to help others in academic, research, and clinical skills.

I greatly appreciate the guidance and knowledge that I have gained from the faculty of the Davis College. I would especially like to thank my supervisor Dr. Janet Tou and labmate Joseph Gigliotti for giving me the opportunity to work with them, despite their hesitancy to work with a dietetic intern. They have been my family away from home and have taught me not only academic, research, and professional skills, but they have also given me many life lessons that I will use for many years to come. I feel extremely privileged to have been able to work with many of the people that I have and most of all to love what I do. Thank you to all and to the others that I may not have listed, but who have also contributed to my success and accomplishments during my time at West Virginia University. 


\section{Page}

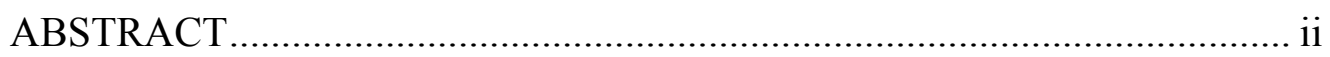

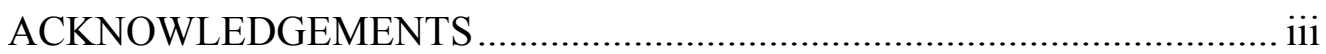

TABLE OF CONTENTS ……………………………........................... iv

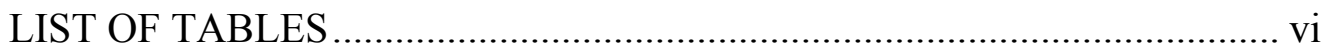

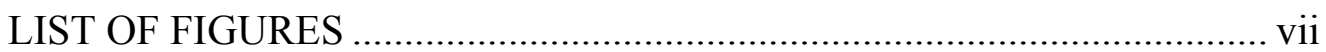

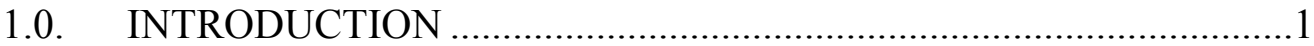

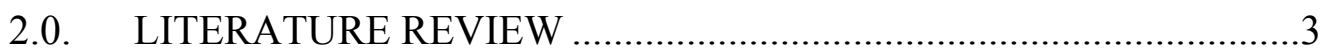

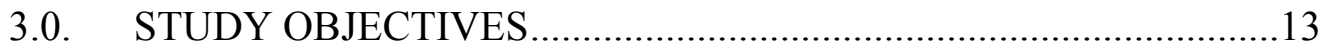

4.0. MATERIALS AND METHODS ....................................................14

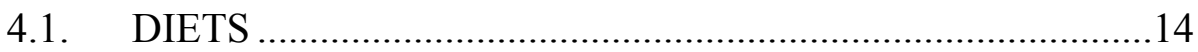

4.2. ANIMAL FEEDING STUDY ……………………..............14

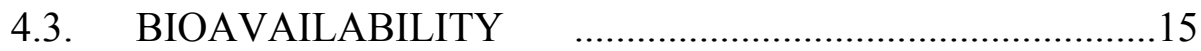

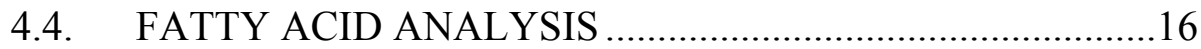

4.5. THIOBARBITURIC ACID REACTIVE SUBSTANCES......17 
4.6. TOTAL ANTIOXIDANT CAPACITY ................................18

4.7. EICOSANOID MEASUREMENTS ...................................18

4.8. $\quad$ STATISTICAL ANALYSIS ..............................................19

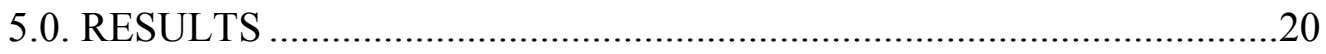

5.1. BIOAVAILABILITY …...............................................20

5.2. FATTY ACID ANALYSIS OF TISSUES ...........................20

5.3. OXIDATIVE STABILITY ..........................................21

5.4. EICOSANOID MEASUREMENTS ...................................21

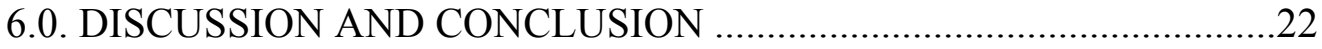

6.1. DISCUSSION ...........................................................22

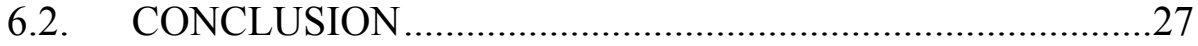

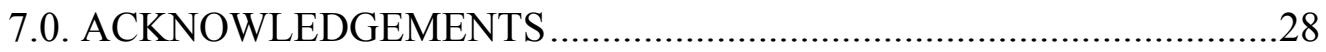

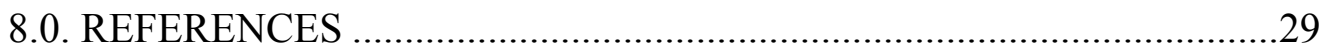




\section{LIST OF TABLES}

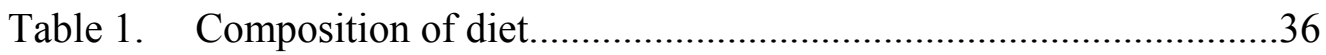

Table 2. Composition of dietary oils.................................................. 37

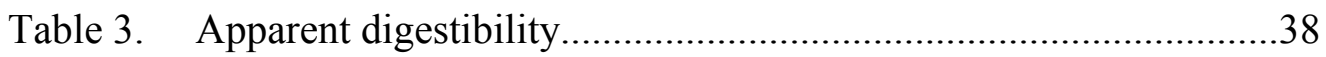

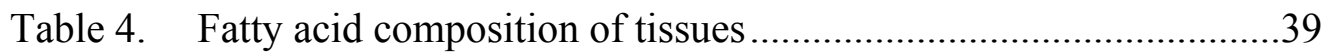

Table 5. Oxidants and antioxidants ....................................................40 


\section{LIST OF FIGURES}

Figure 1. PUFA metabolism..................................................................6

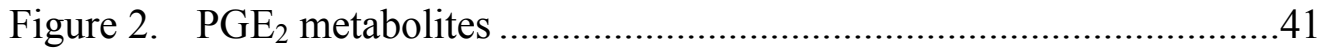

Figure 3. $\mathrm{TXA}_{2}$ metabolites..........................................................42 


\subsection{Introduction}

The beneficial effects of fish have been attributed to the omega-3 polyunsaturated fatty acids ( $\omega$-3 PUFAs) content, docosahexaenoic acid (DHA, 20:6 $\omega$-3) and eicosapentaenoic acid (EPA, 20:5 $\omega-3$ ). However, other components than $\omega-3$ PUFAs may be health beneficial. Feeding protein derived from fish to laboratory animals have been shown to reduce the plasma cholesterol level compared to casein (Jacques et al., 1995). Recently, Wergedahl et al. (2009) reported that the dietary combination of fish protein and lipid may be synergistic. Therefore, consuming fish rather than fish oil supplements may provide optimal health benefits. However, depletion of existing fish stocks and environmental contaminants raises public concern regarding fish consumption.

A potential alternative to fish consumption is to promote consumption of underutilized species such as krill. Krill is a marine crustacean having the largest animal biomass on Earth (Nicol et al., 1987), yet it has remained virtually untapped as a food source. Additionally, krill has been reported to contain lower mercury levels compared to most fish (Nicol et al., 1987). Previously, the lack of an effective technology for meat recovery from krill has hindered its commercial development.

Nutritional evaluation of krill protein concentrate (KPC) indicated it to be a source of high quality protein with the advantage of being a rich source of the $\omega-3$ PUFAs, DHA and EPA (Gigliotti et al., 2008). The $\omega-3$ PUFAs associated with krill are predominantly in phospholipid (PL) form, whereas $\omega-3$ PUFAs in most marine sources are in the form of triacylglycerides (TAG) (Bottino, 1975). Since PLs are digested differently than TAGs, the bioavailability of $\omega-3$ PUFAs from krill may differ. Amate et al. (2001) observed that rats fed PUFAs as egg PLs had lower fecal excretion of DHA 
and higher feed efficiency ratios than rats fed PUFAs in the TAG form, indicating better apparent absorption. In turn, this may affect how efficiently EPA and DHA are incorporated into tissues.

Valenzuela et al. (2005) reported that feeding female rats DHA supplemented in the form of egg phospholipids resulted in higher accretion of DHA in liver and adipose tissue compared to supplementation in the form of TAGs. In contrast, Song et al. (2001) found that rats fed DHA in PL form had lower incorporation of DHA in liver than rats fed DHA in the form of TAGs. Studies regarding tissue incorporation of $\omega$-3 PUFAs from KPC are important because EPA and DHA exert anti-inflammatory properties. Inflammation has been reported to play a role in various diseases states (Calder 2006). EPA and DHA compete with AA for the sn-2 position of phospholipids of cell membranes, affecting the availability of AA in tissues for cleavage by phospholipase $\mathrm{A}_{2}$ and use in eicosanoid production. EPA also competes as a substrate for COX-2 which results in reduction of pro-inflammatory 2-series prostanoids and thromboxanes (Calder 2006).

On the other hand, EPA and DHA are highly susceptible to lipid peroxidation due to their high degree of unsaturation. Song et al. (2001) demonstrated that increased levels of DHA in membrane phospholipids increased Thiobarbituric Acid Reactive Substances (TBARS); however, when provided in PL form did not increase lipid peroxidation. This is important because a source of $\omega-3$ PUFAs that could provide high tissue accretion with the least lipid oxidation would favor maximal health benefits. Therefore, the objective of this study was to investigate the bioavailability and effects of $\omega-3$ PUFAs from KPC on tissue deposition, peroxidation, and lipid metabolism. 


\subsection{Literature Review}

\subsection{Overview of $\omega-3$ PUFAs}

The three most biologically active $\omega-3$ PUFAs are $\alpha$-linolenic acid (ALA, 18:2 $\omega-3)$, EPA, and DHA. The human body cannot synthesize ALA, making it essential. The essential long-chain PUFAs are important because they are precursors of short-lived eicosanoids, which are signaling molecules involved in the inflammatory response. EPA and DHA can be synthesized from ALA if it is provided in the diet. EPA and DHA play a number of important biological roles. However, metabolic conversion of ALA to EPA and DHA is inefficient in humans and varies in other species (Arterburn et al., 2006). EPA and DHA are mainly obtained from marine sources with fish being the most common dietary source. Approximately $19 \%$ of total fatty acids in Antarctic krill are $\omega-3$ PUFAs, with EPA and DHA being particularly abundant (Kolakowska et al., 1994). Total lipids in Antarctic krill contain 15 to $21 \%$ EPA and 9 to 14\% DHA (Phleger et al., 2002). Therefore, acceptance of krill for human consumption has the potential to provide another rich food source of EPA and DHA.

\subsection{Bioavailability of Different Forms of $\omega-3$ PUFAs}

The $\omega$-3 PUFAs in fish are mostly found in the form of TAG, whereas the

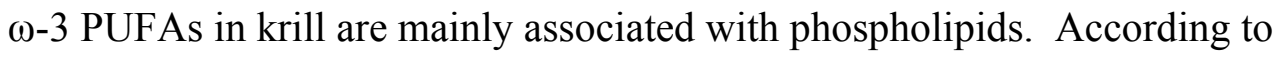
Bottino (1975), about 58\% of total lipids in krill are in the PL form. Dietary PLs have been suggested to have better absorption compared to TAG due to their ability to interact with water in the gut; this may enhance luminal lipid solubilization. Nishioka et al. (2004) demonstrated that administration of 
phosphatidylcholine enhanced lipid absorption in bile-deficient rats. The difference in the position of the fatty acids associated with either PLs or TAG may affect absorption as well. EPA and DHA are typically found at the sn-2 position of PLs and TAGs. In the TAG form, the fatty acids in the sn-1 and sn-3 positions of TAG are cleaved by pancreatic lipase to free fatty acids and the $\omega-3$ PUFA is absorbed as a 2-monoacylglycerol. In the PL form, the EPA or DHA in the sn-2 position is cleaved upon absorption. The $\omega-3$ PUFA is absorbed as a free fatty acid and can be re-esterfied to TAG or 1-lysolechitin in the enterocyte. In the enterocyte, the digestion products of the dietary fats are incorporated into chylomicrons, which are secreted into the lymph then the bloodstream for distribution in the body. Since the $\omega-3$ PUFAs associated with PLs are digested differently than those associated with TAGs, the bioavailability of $\omega-3$ PUFAs in the PL form may differ from $\omega-3$ PUFAs in the TAG form.

Amate et al. (2001) observed that rats fed PUFAs as egg PLs had lower fecal excretion of DHA and higher feed efficiency ratios than rats fed PUFAs in the TAG form, indicating better apparent absorption. However, studies are needed to determine the bioavailability of $\omega-3$ PUFAs from krill.

\subsection{Tissue Incorporation of $\omega-3$ PUFAs}

The $\omega-3$ PUFAs are widely distributed in the body as part of the cell membrane phospholipids (Arterburn et al., 2006). Incorporation of $\omega-3$ PUFAs into liver tissue is especially important since the liver is the main site of fatty acid and lipoprotein metabolism. Amate et al. (2001) compared the distribution of fatty acids in plasma lipoproteins in piglets fed either a control diet, a diet 
containing PUFAs as TAG from tuna and fungal oils, or a diet containing PUFAs as egg PLs. These diets contained $0.6 \mathrm{~g} / 100 \mathrm{~g}$ arachidonic acid (AA, 20:4 $\omega-6$ ) and $0.3 \mathrm{~g} / 100 \mathrm{~g}$ DHA. The authors found that feeding PUFAs as egg PLs resulted in a higher incorporation of dietary AA and DHA into HDL phospholipids.

DHA is particularly abundant in brain and retina tissue and plays an important role in the maintenance of normal neural function (Arterburn et al., 2006; Horrocks et al., 1999). The $\omega-3$ PUFAs that are not incorporated into cell membranes or oxidized for energy are stored in adipose tissue as TAGs. Current dietary recommendations refer to a combined amount of EPA and DHA. KrisEtherton et al. (2002) defined typical recommendations for EPA+DHA as 0.3 to $0.5 \mathrm{~g} /$ day. However, tissue EPA and DHA may not exactly reflect dietary amounts of EPA and DHA because tissue incorporation is affected by total fatty acid content of the diet.

\subsection{Factors Affecting Tissue Incorporation of the $\omega-3$ PUFAs}

Dietary concentration of linoleic acid (LA, 18:2 $\omega-6)$ and ALA should be considered when evaluating tissue composition of EPA and DHA. Concentrations of LA and ALA affect endogenous synthesis of either long-chain $\omega-6$ PUFAs or

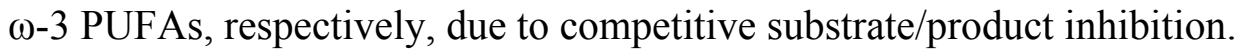
Endogenous synthesis of EPA and DHA from ALA utilizes the enzyme $\Delta-6$ desaturase (Figure 1). However, this enzyme also catalyzes the first step in synthesis of the long-chain $\omega-6$ PUFA, AA, from LA. The high affinity of ALA for $\Delta-6$ desaturase may decrease synthesis of AA from LA (Benatti et al., 2004). 
Figure 1. PUFA Metabolism

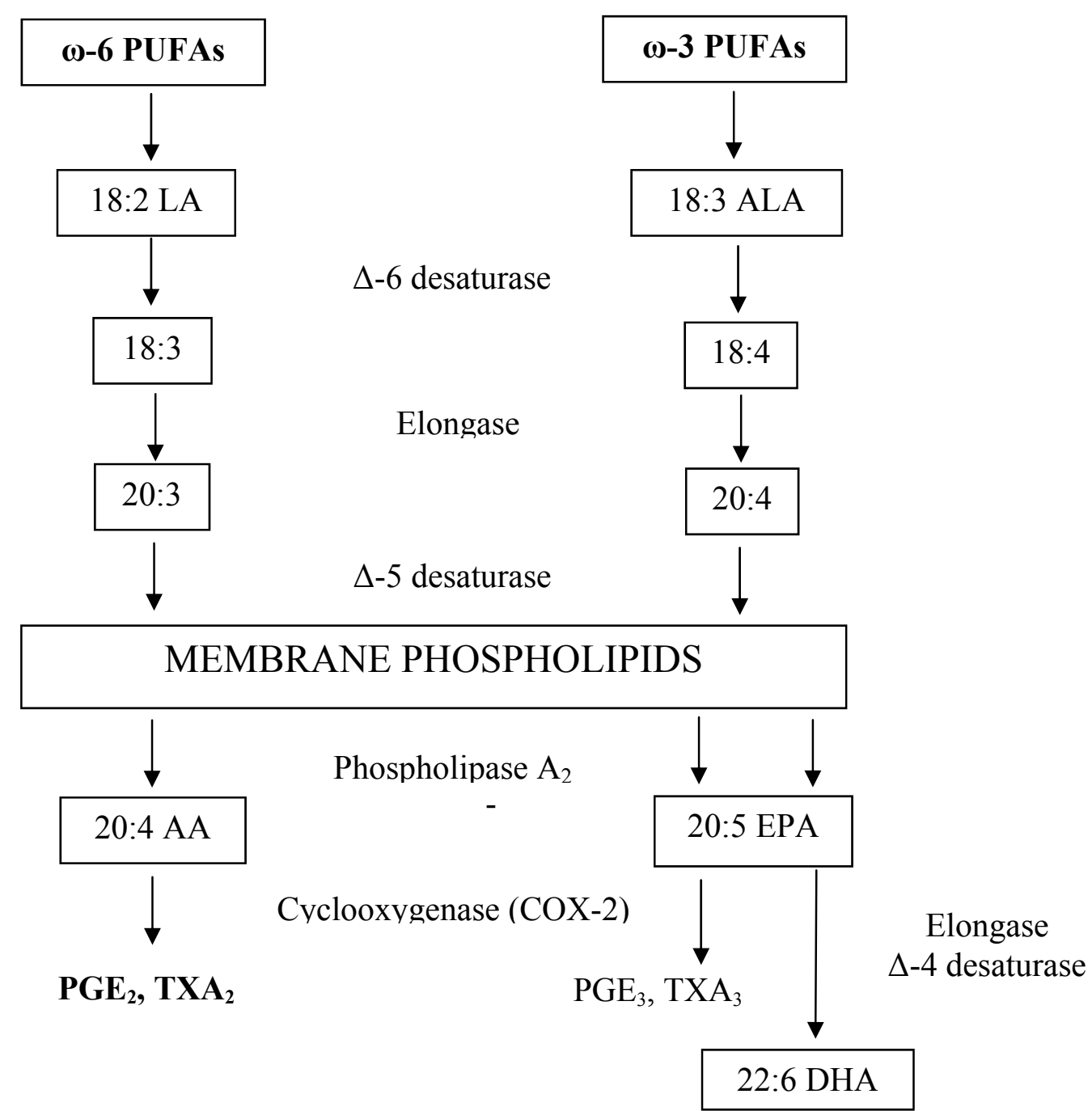

$\mathrm{PGE}=$ Prostaglandin $\mathrm{E}, \mathrm{TXA}=$ thromboxane $\mathrm{A}, \mathrm{PUFA}=$ polyunsaturated fatty acid, $\mathrm{LA}=$ linoleic acid, $\mathrm{ALA}=\alpha$-linolenic acid, $\mathrm{AA}=$ arachidonic acid, $\mathrm{EPA}=$ eicosapentanoic acid, DHA = docosahexanoic acid 
Supplementation of DHA has also been shown to decrease metabolites of LA and ALA in plasma lipid profiles (Emken et al., 1999). AA is the biological precursor for pro-inflammatory eicosanoids; therefore, too much AA in tissues could increase risk of cardiovascular disease (CVD) and other inflammatory diseases. AA competes with EPA and DHA for the sn-2 position in phospholipids of cell membranes (Figure 1). It has been shown that supplementation of EPA and DHA with no AA increases tissue incorporation of EPA and DHA while decreasing AA (Innis et al., 1995). Dietary EPA and DHA supplementation may then decrease endogenous synthesis of the pro-inflammatory $\omega-6$ PUFA, AA, from the 18 carbon precursors, LA, while providing the less inflammatory longchain $\omega$-3 PUFAs, resulting in decreased CVD risk. Similarly, high concentration of the long-chain $\omega-6$ AA affects tissue incorporation of the long-chain $\omega-3$ PUFAs, EPA and DHA.

Dietary source may also affect how efficiently EPA and DHA are incorporated into tissues. Valenzuela et al. (2005) compared the effects of different DHA sources on tissue accretion in female rats. DHA supplementation in the form of egg PLs resulted in higher accretion of DHA in liver and adipose tissue compared to supplementation in the form of TAGs or ethyl esters. According to these results, DHA associated with PLs is more efficiently incorporated into tissues. However, Song et al. (2001) found that rats fed DHA in PL form had lower incorporation of DHA in liver and plasma phospholipids than rats fed DHA in the form of TAGs or ethyl esters. Clearly, more studies are needed to confirm the effect of different dietary sources of $\omega-3$ PUFAs on tissue 
incorporation because they contribute to membrane fluidity and serve as precursors for less inflammatory eicosanoids.

Tissue incorporation of EPA and DHA may also differ from dietary content due to interconversion between EPA and DHA in the body. Innis et al. (1995) performed a study comparing the effect of marine versus freshwater fish oil on fatty acid incorporation into the tissues of growing rats. The marine oil diet contained similar DHA as the freshwater fish oil diet, but lower AA and higher EPA. The results showed that despite having a similar DHA content as the freshwater fish oil diet, the marine oil diet had higher liver, brain, kidney, and heart tissue accretion of DHA. The authors attributed these results to a high conversion rate of EPA to DHA in the marine oil diet. Murphy et al. (1997) found that guinea pigs fed a diet with higher EPA than DHA had higher heart tissue accretion of DHA compared to EPA. These authors also suggested that this was due to a high conversion of EPA to DHA. However, these diets contained neither the EPA or DHA precursor, ALA, or the $\omega-6$ PUFA, AA, and minimal amounts of LA.

Based on these study results, levels of the other $\omega-3$ and $\omega-6$ PUFAs must be taken into consideration when evaluating tissue incorporation of EPA and DHA from KPC. The lipid component of KPC contains relatively equal amounts of EPA and DHA ( $12 \%$ total fatty acids each) while providing a minimal amount of AA ( 1.2\% total fatty acids) (Gigliotti et al., 2008). It also contains small amounts of the PUFA $\omega-3$ precursor, ALA ( $1.5 \%$ total fatty acids), and the $\omega-6$ PUFA precursor, LA ( $\sim 3.1 \%$ total fatty acids) (Gigliotti et al., 2008). To our 
knowledge, no studies have examined tissue incorporation of EPA and DHA in response to KPC supplementation.

\subsection{Oxidative Stability of $\omega-3$ PUFAs}

Increased tissue amounts of $\omega-3$ PUFAs have been shown to produce a number of health benefits. However, the $\omega-3$ PUFAs are also highly susceptible to oxidation due to their high degree of unsaturation. Auto-oxidation of PUFA in membrane phospholipids generates a mixture of epoxides, hydroperoxides, and cyclic peroxides (Porter et al., 1995). DHA is particularly susceptible to peroxidation because it contains 6 double bonds. Saito et al. (2002) found that feeding rats $8.4 \%$ total energy as purified DHA for 30 days significantly increased lipid peroxidation as evidenced by increased thiobarbituric acid reactive substances (TBARS).

Song et al. (2001) demonstrated that increased levels of DHA in membrane phospholipids increased TBARS in rats fed DHA as either TAG or ethyl esters. The authors also found that there was a greater loss of $\omega-3$ PUFAs than $\omega-6$ PUFAs as a result of lipid peroxidation, indicating that $\omega-3$ PUFAs are more susceptible to lipid peroxidation than $\omega-6$ PUFAs. Interestingly, Song et al. (2001) found that DHA provided in PL form did not increase lipid peroxidation. These results suggested that $\omega-3$ PUFAs provided as PLs may have higher stability against peroxidation than DHA provided as TAG or ethyl esters. This is important because a source of $\omega-3$ PUFAs that could provide high tissue accretion with the least lipid oxidation would favor maximal health benefits. Krill oil is high in PLs and since the $\omega-3$ PUFAs associated with PLs may be more stable 
against lipid peroxidation than tissue associated with TAG, it is important to evaluate the effect of $\omega-3$ PUFAs from KPC on oxidative stability.

Large amounts of lipid auto-oxidation products contribute to atherogenesis (Porter et al., 1995). Leigh-Firbank et al. (2002) found that supplementation of EPA + DHA increased LDL-cholesterol and oxidation of LDL. Oxidized LDL plays a central role in the initiation as well as the progression of the atherogenic process (Gropper et al., 2005). These studies suggested that increased levels of $\omega$ 3 PUFAs induce lipid peroxidation and may contribute to atherosclerosis.

Endogenous antioxidants function to defend against unstable free radicals such as reactive oxygen species that cause damage to lipids, protein, and DNA (Halliwell, 1996). However, increased lipid peroxides may exhaust the body's antioxidant defense system. Disturbance in the balance between reactive oxygen species such as lipid peroxides and antioxidants results in oxidative stress.

Oxidative stress increases the risk of inflammatory diseases such as CVD. Therefore, it is also critical to determine the effect of $\omega-3$ PUFAs from KPC on tissue oxidation and the body's antioxidant defense system.

\subsection{Effect of $\omega$-3 PUFAs on Cardiovascular Health}

The prevalence of CVD among Americans has led to increased importance of dietary intervention and prevention. The $\omega-3$ PUFAs have received much attention due to reports of anti-inflammatory properties and improvement of the plasma lipids and lipoprotein profile. EPA and DHA have been shown to produce hypotriglyceridemic effects (Grimsgaard et al., 1997). In vitro studies have suggested that EPA may be more effective in lowering serum TAG than DHA 
(Leigh Firbank et al., 2002; Rambjor et al., 1996; Wong et al., 1989). However, other studies have found that EPA and DHA exert similar hypotriglyceridemic effects (Woodman et al., 2002; Grimsgaard et al., 1997).

EPA and DHA have been found to decrease plasma cholesterol (Froyland et al., 1996). DHA has been found to reduce HMG-CoA reductase activity, which could contribute to a hypocholesterolemic effect (Froyland et al., 1996). EPA and DHA have also been shown to affect plasma lipoproteins. Studies evaluating the effects of EPA and DHA on plasma lipoproteins are inconclusive. DHA has been suggested to increase LDL-cholesterol (Leigh-Firbank et al., 2002; Mori et al., 2000). Rambjor et al. (1996) attributed increased LDL-cholesterol to EPA.

Bunea et al. (2004) compared the effects of providing subjects with supplement of fish oil or krill oil on serum lipid and lipoprotein profiles. According to this study, daily supplementation of 1 to 1.5 grams of krill oil for 90 days resulted in a greater $(P<0.001)$ decrease in serum cholesterol and increased HDL compared to subjects who received 3 grams of fish oil per day. Other studies have shown that DHA decreased HDL-cholesterol (Saito et al., 2002). Gigliotti et al. (2008) found that KPC decreased $(P=0.004)$ HDL-cholesterol in rats.

The cardioprotection provided by EPA and DHA may not be predominantly due to the effects on plasma lipoproteins. Antithrombotic effects of fish oil have been attributed to decreases in platelet aggregation, thromboxane $\mathrm{A}_{2}$ (TXA ${ }_{2}$ ), and blood viscosity (Benatti et al., 2004). Park et al. (2002) found that EPA decreased mean platelet volume, an early step in platelet aggregation. Engstrom et al. (1996) found that administration of $30 \mathrm{~g} / \mathrm{d}$ of fish oil containing 
17\% EPA and $11.7 \%$ DHA decreased the stable $\mathrm{TXA}_{2}$ metabolite, thromboxane $\mathrm{B}_{2}\left(\mathrm{TXB}_{2}\right)$, in men. DHA has been shown to have hypotensive effects and decrease cardiac arrhythmias (Benatti et al., 2004; Horrocks et al., 1999). Both EPA and DHA interfere with the production of inflammatory eicosanoids from AA through the cyclooxygenase (COX) pathway. EPA competes as a substrate for COX-2 and results in the production of less inflammatory 3-series prostanoids and 5-series leukotrienes. Dusing et al. (1997) demonstrated this using administration of $3.6 \mathrm{~g} / \mathrm{d}$ EPA and $2.4 \mathrm{~g} / \mathrm{d}$ DHA in humans; this significantly decreased urinary excretion of prostaglandin $\mathrm{E}_{2}\left(\mathrm{PGE}_{2}\right)$ while increasing prostaglandin $\mathrm{E}_{3}$.

EPA and DHA incorporated into the tissues may differ depending on the source. Thus, the beneficial effects of $\omega-3$ PUFAs may depend more on tissue composition than diet composition. Therefore, it is important to determine the bioavailability, tissue deposition, oxidative stability, and lipid metabolism of EPA and DHA from dietary KPC. 


\subsection{Study Objectives}

Objective 1. To determine the bioavailability and tissue deposition of $\omega-3$ PUFAs from dietary KPC.

Objective 2. To determine the effects of $\omega-3$ PUFAs from dietary KPC on oxidative stress.

Objective 3. To determine the effects of $f \omega-3$ PUFAs from dietary KPC on lipid metabolism. 


\subsection{Materials and Methods}

\subsection{Diets}

Whole frozen Antarctic krill (Euphausia superba) were purchased from Krill Canada (Langley, BC, Canada). KPC was recovered from whole krill using an isoelectric solubilization/precipitation method (Chen \& Jaczynski, 2007). The proximate composition of recovered KPC after freeze-drying was $77.7 \%$ crude protein, $8.1 \%$ total lipid, and 4.4\% total ash (Gigliotti et al., 2008). Diets were based on a standard purified AIN-93G diet (Reeves et al., 1993). Modifications of the AIN-93G diet consisted of replacing soybean oil with corn oil and $10 \%$ crude protein supplied as KPC or casein (Table 1). Replacement of the protein as either KPC or casein was corrected for protein and lipids so that the diets were isocaloric and isonitrogenous. Both diets contained 5.3\% total lipid. The casein diet contained $5.3 \%$ corn oil $(\mathrm{CO})$ whereas the KPC contained $0.9 \%$ krill oil from KPC and $4.4 \%$ corn oil $(\mathrm{KO}+\mathrm{CO})$. Fatty acid analysis of the diets is shown in Table 2. Diets containing KPC were prepared weekly and kept stored at $4^{\circ} \mathrm{C}$.

\subsection{Animal Feeding Study}

All animal procedures were approved by the Animal Care and Use Committee at West Virginia University and were conducted in accordance with the guidelines set forth by the Institute of Laboratory Animal Resources Commission on Life Sciences for the Care and Use of Laboratory Animals (1996). Young (28 d) female Sprague-Dawley rats were purchased from Taconic Farms (Rockville, MD). Upon arrival at the animal care facility, rats were individually housed in metabolic cages to determine food intake and to collect 
urine and feces. Rats were kept caged in rooms maintained at $21^{\circ} \mathrm{C}$ with a $12 \mathrm{~h}$ light/dark cycle. During a $14 \mathrm{~d}$ acclimation period, animals were given ad libitum access to deionized distilled water $\left(\mathrm{ddH}_{2} \mathrm{O}\right)$ and AIN-93G diet (Harklan Teklad; Indianapolis, IN). Following the $14 \mathrm{~d}$ acclimation period, rats (n=10/group) were randomly assigned to be fed ad libitum either $10 \%$ casein with $5.3 \% \mathrm{CO}$ or KPC with $0.9 \% \mathrm{KO}$ and $4.4 \% \mathrm{CO}(\mathrm{KO}+\mathrm{CO})$. Food intake was measured biweekly. At the end of the 4 weeks, rats were euthanized by $\mathrm{CO}_{2}$ inhalation.

Retroperitoneal and gonadal fat pads, brain, and liver were dissected and weighed.

There were no significant differences in food intake (Gigliotti et al., 2008). There were no significant differences in final body weights between rats fed KPC diet with $\mathrm{KO}+\mathrm{CO}$ compared to rats fed casein diet with $\mathrm{CO}$ (Gigliotti et al., 2008). Rats fed $\mathrm{KO}+\mathrm{CO}$ had higher retroperitoneal $(P=0.02)$ and gonadal $(P=0.03)$ fat pad weights than rats fed CO (Gigliotti et al., 2008). There were no significant differences in brain or liver weights between $\mathrm{KO}+\mathrm{CO}$ and $\mathrm{C}+\mathrm{CO}$ fed rats (Gigliotti et al., 2008).

\subsection{Bioavailability}

Bioavailability was measured by determining apparent digestibility of dietary lipid during the final week of the study. Fecal samples were freeze-dried for $48 \mathrm{~h}$. Total fecal lipid was determined by Soxhlet extraction. Apparent digestibility (\%) was determined using the formula [(lipid intake-fecal lipid)/(lipid intake)] x 100 (Deuchi et al., 1994). Similarly, apparent digestibility (\%) of individual fatty acids were determined using the formula [(fatty acid intake-fecal fatty acids)/(fatty acid intake)] x 100 . 


\subsection{Fatty Acid Analysis}

Lipids were extracted from the gonadal and retroperitoneal fat pads, liver, brain, and feces according to the method by Bligh and Dyer (1959). All tissue samples were conducted in duplicates. Tissues were weighed and $48 \mu \mathrm{L}$ of heptadecenoic acid (17:1) was added as an internal standard. Weighed samples were added to Tris/EDTA buffer $\mathrm{pH}$ 7.4. A chloroform:methanol:acetic acid $(2: 1: 0.15 \mathrm{v} / \mathrm{v} / \mathrm{v})$ solution was added to the samples. Samples were centrifuged at $900 \times \mathrm{g}$ for 10 minutes at $10^{\circ} \mathrm{C}$ and the bottom chloroform layer was collected. The collected chloroform was then filtered through 1-phase separation filters to remove any remaining water and precipitated material. The remaining layer was then mixed with chloroform:methanol $(4: 1 \mathrm{v} / \mathrm{v})$ and centrifuged at $900 \times g$ for 10 min at $10^{\circ} \mathrm{C}$. The chloroform layer was collected and filtered. The extracted lipid was dried under nitrogen gas.

The extracted lipid samples were transmethylated following the procedure described by Fritsche and Johnston (1990). Extracted fatty acids were methylated by adding $4 \% \mathrm{H}_{2} \mathrm{SO}_{4}$ in anhydrous methanol to the dried lipid samples followed by incubation in a $90^{\circ} \mathrm{C}$ water bath for 60 minutes. Samples were cooled to room temperature and $3 \mathrm{~mL}$ of deionized distilled $\mathrm{H}_{2} \mathrm{O}$ was added to stop the reaction. Chloroform was added to the methylated sample. Samples were again dried under nitrogen gas, and iso-octane $(3 \mathrm{~mL})$ was used as a diluent.

The methylated lipid samples were analyzed by gas chromatography (CP3800, Varian Inc., Walnut Creek, CA) using an initial temperature of $140^{\circ} \mathrm{C}$ held for 5 minutes and then increased $1{ }^{\circ} \mathrm{C}$ per min to a final temperature of $220^{\circ} \mathrm{C}$. A 
wall-coated open tubular (WCOT) fused silica capillary column (Varian Inc., Walnut Creek, CA) was used to separate fatty acid methyl esters (FAME) with CP-Sil 88 (Varian Inc., Walnut Creek, CA) as the stationary phase. Nitrogen was used as the carrier gas, and total separation time was 110 minutes. Quantitative 37 Component FAME Sigma Mix (Supelco, Bellefonte, PA) was used to identify fatty acid composition. Fatty acids were identified using retention time and peak area counts with Star GC Workstation computer software (Varian Inc., Walnut Creek, CA).

\subsection{Thiobarbituric Acid Reactive Substances (TBARS)}

TBARS were measured using a commercially available enzyme immunoassay (EIA) kit (Cayman Chemical, Ann Arbor, MI). Urine collected at baseline and on the final week (week 4) of the feeding study was used to measure lipid peroxidation. Homogenates of gonadal and retroperitoneal fat pads, liver, and brain were used to measure lipid peroxidation in these tissues. Samples were mixed with sodium dodecyl sulfate (SDS) solution and a color reagent containing thiobarbituric acid (TBA), acetic acid, and sodium hydroxide. Samples were incubated for 60 minutes in a $90^{\circ} \mathrm{C}$ water bath and then incubated in an ice bath for 10 minutes to stop the reaction. Following centrifugation for 10 minutes at $1,600 \mathrm{x} g$ at $4{ }^{\circ} \mathrm{C}$, samples were measured colorimetrically. Absorbance was read at $540 \mathrm{~nm}$ using a Spectramax Plus microplate reader (Molecular Devices, CA) and values were expressed as $\mu \mathrm{M}$ MDA (malondialdehyde). 


\subsection{Total Antioxidant Capacity}

Total antioxidant capacity was measured according to a commercially available EIA Antioxidant Assay kit (Cayman Chemical, Ann Arbor, MI). Urine collected from the baseline and final weeks was diluted with $5 \mathrm{mM}$ potassium phosphate buffer containing $0.9 \%$ sodium chloride and $0.1 \%$ glucose at $\mathrm{pH} 7.4$ (1:20 v/v). Trolox (6-Hydroxy-2,5,7,8-tetramethylchroman-2-carboxylic acid), a water soluble tocopherol analogue, was added to standard wells, and sample diluted to 1:20 were added in duplicates to wells. Metmyoglobin and ABTS (2,2'Azino-di-[3-ethylbenzthiazoline sulphonate]) were then added to all wells. To initiate the reaction, hydrogen peroxide was added to each well. Samples were then incubated at room temperature on a shaker for 5 minutes. Absorbance was read at $750 \mathrm{~nm}$ using a Spectramax Plus microplate reader (Molecular Devices, CA). Antioxidant concentration was expressed as mM Trolox.

\subsection{Eicosanoid Measurements}

The effect of $\omega$-3 PUFAs from KPC on lipid metabolism was determined by measuring urinary eicosanoids. Efficacy in reducing the inflammatory AA product, $\mathrm{PGE}_{2}$, was measured in urine using to Cayman's Prostaglandin E Metabolite Enzyme Immunoassay (Cayman Chemical, Ann Arbor, MI).

Effect on reducing thrombosis was determined by measuring prothrombotic AA thromboxanes. TXA 2 is short-lived, therefore a stable metabolite 11-dehydro $\mathrm{TXB}_{2}$ was measured in the urine using commercial enzyme immunoassay kit (EIA, Cayman Chemical, Ann Arbor, MI). 


\subsection{Statistical Analysis}

The Student's t-test was used to compare differences between treatment groups, and Mann-Whitney Rank Sum test was performed on data not normally distributed. Differences were considered significant at $P<0.05$. Results are expressed as mean \pm SEM. Results were analyzed using SigmaStat 3.1 statistical software program (Systat Software Inc., San Jose, CA). 


\subsection{Results}

\subsection{Lipid and Fatty Acid Bioavailability}

No significant difference was found in total lipid intake, total lipid content of feces, or apparent digestibility (\%) of dietary total lipid between groups (Table 3). Rats fed $\mathrm{KO}+\mathrm{CO}$ had a lower $(P=0.001)$ intake of $\mathrm{LA}$ and higher $(P<0.05)$ intake of ALA, AA, EPA, and DHA. There were no differences in fecal excretion of LA or ALA by rats fed $\mathrm{KO}+\mathrm{CO}$ compared to rats fed CO. Apparent digestibility (\%) of the AA precursor, LA, was significantly decreased $(P=0.02)$ in rats fed $\mathrm{KO}+\mathrm{CO}$ compared to rats fed $\mathrm{CO}$, while apparent digestibility (\%) of the long-chain $\omega$-3 PUFA precursor, ALA, was unaffected. Rats fed $\mathrm{KO}+\mathrm{CO}$ had a low apparent digestibility (\%) of AA (22.75 \pm 6.45$)$, moderate apparent digestibility (\%) of EPA (70.12 \pm 3.52$)$ and high apparent digestibility (\%) of DHA $(93.42 \pm 1.64)$.

\subsection{Fatty Acid Analysis of Tissues}

To investigate the effect of $\mathrm{KO}+\mathrm{CO}$ on tissue fatty acid deposition, analysis was performed on retroperitoneal and gonadal fat pads, liver, and brain (Table 4). There were no significant differences in LA or ALA tissue content between groups. Deposition of AA was decreased in rats fed $\mathrm{KO}+\mathrm{CO}$ in retroperitoneal fat pad $(P=0.002)$ and liver tissue $(P<0.001)$. Rats fed $\mathrm{KO}+\mathrm{CO}$ also displayed a tendency $(P=0.056)$ for lower AA gonadal fat pad deposition. No difference in AA brain deposition was found between groups.

Rats fed $\mathrm{KO}+\mathrm{CO}$ had significantly higher tissue deposition of EPA in retroperitoneal and gonadal fat pads $(P=0.004)$ and liver $(P<0.001)$ compared to 
rats fed CO only. EPA was not present in detectable amounts in brain tissue of either group. Tissue deposition of DHA was significantly increased in rats fed $\mathrm{KO}+\mathrm{CO}$ in retroperitoneal $(P=0.003)$ and gonadal $(P=0.021)$ fat pads, liver $(P<0.001)$, and brain $(P=0.003)$ compared to rats fed $\mathrm{CO}$ only.

\subsection{Oxidative Stability}

To determine the effect of $\omega-3$ PUFAs provided by KPC on lipid oxidation, TBARS were measured in various tissues (Table 5). There were no significant differences in retroperitoneal fat pad, liver, or brain TBARS between the groups. Rats fed $\mathrm{KO}+\mathrm{CO}$ had significantly decreased $(P=0.032)$ TBARS in the gonadal fat pad compared to rats fed CO only. No significant difference was found in baseline and final TBAR concentrations in urinary samples between groups. However, rats fed $\mathrm{KO}+\mathrm{CO}$ displayed a trend $(P=0.06)$ toward lower final urinary TBARS.

Total antioxidant capacity was measured to determine whether the $\omega-3$ PUFAs provided by KPC had an effect on endogenous antioxidant function (Table 5). There were no differences between groups or between baseline and final urinary total antioxidant capacity.

\subsection{Eicosanoid Measurements}

Urinary metabolites of the pro-inflammatory AA product, $\mathrm{PGE}_{2}$, were reduced $(P=0.009)$ in rats fed $\mathrm{KO}+\mathrm{CO}$ compared to rats fed $\mathrm{CO}$ only (Figure 2$)$. There was a tendency $(P=0.054)$ for reduced $\mathrm{TXA}_{2}$ metabolite, 11-dehydro $\mathrm{TXB}_{2}$, in rats fed $\mathrm{KO}+\mathrm{CO}$ (Figure 3 ). 


\subsection{Discussion \& Conclusion}

\subsection{Discussion}

KPC provides a high quality protein and a rich source of the $\omega-3$ longchain PUFAs (LCPUFAs), EPA and DHA. KPC consisting of $0.9 \% \mathrm{KO}$ blended with $\mathrm{CO}$, which contains negligible amounts of AA, EPA, and DHA, resulted in measurable concentrations. Most studies reporting increased EPA and DHA tissue deposition have used large doses of pure oil (Arterburn et al., 2006). Low doses and mixtures of oil are more representative of the human diet. AA, EPA, and DHA can also be synthesized in the body from the essential fatty acids. Sufficient dietary ALA intake promotes EPA and DHA synthesis, and LA promotes AA synthesis. ALA content was slightly higher and LA content lower in $\mathrm{KO}+\mathrm{CO}$ compared to $\mathrm{CO}$ alone. Whether altered dietary fatty acid affects incorporation into tissues and conversion to other fatty acids will depend on the bioavailability of the fatty acid.

Bioavailability of EPA and DHA precursor, ALA, was low for both oils. Apparent digestibility of ALA was lower in rats fed $\mathrm{KO}+\mathrm{CO}(49 \%)$ compared to $\mathrm{CO}(63 \%)$. However, $\mathrm{KO}+\mathrm{CO}$ provided DHA with high apparent digestibility (93\%) and EPA with moderate apparent digestibility (70\%). Although CO contains negligible AA, bioavailability of the AA precursor, LA, was high. Rats fed $\mathrm{KO}+\mathrm{CO}$ had significantly lower apparent LA digestibility (93\%) compared to rats fed $\mathrm{CO}(96 \%)$. This was due to lower $(P=0.001)$ intake of LA in the $\mathrm{KO}+$ $\mathrm{CO}$ diet and absences of difference in fecal excretion between the groups. Also, 
the AA provided by $\mathrm{KO}+\mathrm{CO}$ showed low apparent digestibility (23\%).

Differences in fatty acid bioavailability may be due to fatty acids in KO being associated with PLs and CO with TAGs.

Animal and human studies have indicated that DHA and AA are important to the development of the central nervous system (Innis, 2007). AA and DHA were detectable in the brains of rats fed $\mathrm{CO}$ despite negligible amounts in the diet. Thus, it is likely that conversion of LA and ALA by the desaturation-elongation pathway occurred in neural tissue. However, studies have suggested that conversion of essential fatty acids to the LC PUFAs may not be sufficient to support the needs of growing infants. To ensure adequate intake, infant formulas are often supplemented with DHA in the form of TAGs or egg PLs. In our study, growing rats fed $\mathrm{KO}+\mathrm{CO}$ had higher $(P=0.003)$ DHA deposition in brain tissue compared to rat fed CO. Clinical trials with premature infants reported that DHA provided as egg PL resulted in better absorption than DHA provided as TAGs (Carnielli et al., 1998).

Innis et al. (1995) reported that feeding rats a diet composed of a $2 \%$ safflower oil and $10 \%$ marine fish oil blend ( $0.9 \%$ AA; $15.1 \%$ EPA; $7.3 \%$ DHA) for 4 weeks increased brain EPA and DHA and decreased AA compared to rats fed $12 \%$ safflower oil. In our study, the $0.9 \% \mathrm{KO}$ from KPC provided $1.5 \% \mathrm{AA}$, $12.5 \%$ EPA, and $12.7 \%$ DHA for 4 weeks, but did not lead to detectable brain EPA. According to Arterburn et al. (2006), EPA is typically found in low to nondetectable amounts in brain tissue. Additionally, feeding rats $\mathrm{KO}+\mathrm{CO}$ for 4 weeks increased DHA without decreasing AA brain content. This is important 
because DHA in conjunction with AA is considered necessary to support proper growth and development during the early and rapid growth phase of life (Mathews et al., 2002).

The nervous system is the organ with the second largest PUFA concentration of lipids, only exceeded by adipose tissue (Benatii et al., 2004). Dietary fatty acids not used for incorporation into cell membrane phospholipids, oxidation, or other metabolic purposes are stored in adipose tissue as TAG. In human adipose tissue, LA is the most abundant PUFA at $~ 12-16 \%$ of fatty acids and ALA is the most abundant $\omega-3$ PUFA at $\sim 1 \%$ (Arterburn et al., 2006). In our animal study, LA and ALA content of fat pads were similar in rats fed both diets. EPA and DHA were increased in fat pads of rats fed $\mathrm{KO}+\mathrm{CO}$; whereas, neither of these long-chain $\omega-3$ PUFAs were detectable in rats fed CO. Therefore, adipose tissue reflected the dietary intake of fatty acids. Detectable AA content in the fat pads of rats fed AA-deficient $\mathrm{CO}$ diet indicated conversion from LA. Lower AA deposition in the fat pads of $\mathrm{KO}+\mathrm{CO}$ compared to $\mathrm{CO}$ fed rats may have resulted from poor bioavailability of AA in the PL form.

The liver is the main site of fatty acid synthesis and conversion (Arterburn et al., 2006). ALA was not detectable in liver tissue of rats fed either diet; this may be due to low apparent digestibility of the ALA in both diets and conversion to DHA. This is indicated by measureable DHA content in the liver tissue of rats fed the DHA-deficient CO diet. Werner et al. (2004) found that feeding ALA in the PL form increased DHA content in the liver compared to the TAG form; the authors attributed this to greater bioavailability. However, this study was 
conducted in essential fatty acid deficient mice; whereas, the rats in our study were provided sufficient efficient fatty acids. Froyland et al. (1996) reported minimal amounts of ALA in liver phospholipids of Wistar rats and these amounts did not differ with supplementation of EPA, DHA, or CO for three months. Therefore, the higher liver EPA and DHA content in the rats fed $\mathrm{KO}+\mathrm{CO}$ was due to KO providing a dietary source of EPA and DHA.

Measureable AA in the liver tissue of rats fed the AA-deficient CO diet suggests conversion from LA. Rats fed $\mathrm{KO}+\mathrm{CO}$ diet had reduced AA deposition in the liver compared to rats fed $\mathrm{CO}$ despite AA being provided in the diet. Tissue AA content is affected by EPA and DHA due to competition for the sn-2 position of phospholipids in cell membranes (Gropper et al., 2005). Therefore, reduced liver $\mathrm{AA}$ in rats fed $\mathrm{KO}+\mathrm{CO}$ compared to $\mathrm{CO}$ may be due to the poor bioavailability of AA as well as competitive inhibition with EPA and DHA.

Froyland et al. (1996) found that feeding male rats a diet with either $94 \%$ of total fatty acids as EPA ethyl esters led to a 17 -fold increase in liver EPA and 41-fold increase in epididymal fat pad EPA compared to CO. The authors also found that feeding $91 \%$ of total fatty acids as DHA ethyl esters led to a 3-fold increase in liver DHA and 11-fold increase in epididymal fat pad DHA compared to corn oil. In the current study, the AA, EPA, and DHA from KO individually contributed to less than $0.01 \%$ of total fatty acids were still capable of increasing tissue $\omega-3$ LCPUFAs and lowering liver and adipose $\omega-6$ long chain PUFAs concentrations. This is important because it shows low dose $\omega-3$ LCPUFAs in PL form produce similar effects to supplements providing high doses. 
Reduction in tissue content of AA has been suggested for health benefits because higher AA concentration provides increased substrates for formation of pro-inflammatory eicosanoids such as $\mathrm{PGE}_{2}$ and $\mathrm{TXA}_{2}$ in response to cellular injury. Based on the current study, feeding the $\mathrm{KO}+\mathrm{CO}$ diet reduced urinary metabolites of $\mathrm{PGE}_{2}$ and $\mathrm{TXA}_{2}$. This is consistent with previous studies showing that supplementation of either EPA or DHA decreases AA pro-inflammatory eicosanoid production. Kelley et al. (1999) found that supplementation of $6 \mathrm{~g} / \mathrm{d}$ DHA in healthy human subjects decreased serum $\mathrm{PGE}_{2}$ by $60-75 \%$ compared to the control diet. The current study suggests that an EPA level of 0.01\% and DHA level of $0.01 \%$ of the total diet has the ability to decrease $\mathrm{PGE}_{2}$ metabolites and $\mathrm{TXA}_{2}$ metabolites when compared to rats fed CO. In the current study, it is possible that a difference in metabolism and tissue incorporation associated with fatty acids in the PL form may be partially responsible for the large reduction seen even with the low dietary contribution of EPA and DHA.

EPA and DHA are highly susceptible to lipid peroxidation due to their high degree of unsaturation. In our study, the increased tissue incorporation of EPA and DHA in rats fed $\mathrm{KO}+\mathrm{CO}$ did not increase tissue or urinary TBARS. The lack of effect on oxidative stress seen in the current study may then be due to either a smaller dietary amount of EPA and DHA or difference in physiochemical form used. In support, Song et al. (2001) observed increased levels of DHA in membrane phospholipids did not increase lipid peroxidation when DHA was provided in the PL form. Based on these results, the $\omega-3$ PUFA content of KPC does not contribute significantly to oxidative stress. 


\subsection{Conclusions}

A source of $\omega$-3 PUFAs that provides high tissue accretion with the least lipid oxidation favors maximal health benefits. The $\omega-3$ PUFAs associated with KPC increased tissue incorporation without changing oxidative stability. The $0.9 \% \mathrm{KO}$ provided by KPC was able to decrease AA tissue accretion and proinflammatory eicosanoid metabolites. The results suggest that consumption of KPC provides a healthy and sustainable alternative to fish or fish oil supplement. 


\subsection{Acknowledgements}

We would like to thank Drs. Jacek Jaczynski and Cindy Fitch for their review of the manuscript. We also thank Joey Gigliotti, Kylash Konanur, and Stephanie Altman for their technical support. 


\subsection{References}

Amate, L., Gil, A., \& Ramírez, M. (2001). Feeding Infant Piglets Formula with LongChain Polyunsaturated Fatty Acids as Triglycerols of Phospholipids Influences the Distribution of These Fatty Acids in Plasma Lipoprotein Fractions. The Journal of Nutrient Metabolism, 131, 1250-1255.

Arterburn, L.M., Hall, E.B., \& Oken, H. (2006). Distribution, Interconversion, and Dose Response of n-3 Fatty Acids in Humans. The American Journal of Clinical Nutrition, $83,1467 \mathrm{~S}-1476 \mathrm{~S}$.

Benatti, P., Peluso, G., Nicolai, R., \& Calvani, M. (2004). Polyunsaturated fatty acids: biochemical, nutritional and epigenetic properties. Journal of the American College of Nutrition, 23, 281-302.

Bligh, E.G. \& Dyer, W.J. (1959). A rapid method of total lipid extraction and purification. Canadian Journal of Biochemistry and Physiology, 37, 911-917.

Bottino, N.R. (1975). Lipid Composition of Two Species of Antarctic Krill: Euphausia superba and E. crystalorophias. Comparative Biochemistry and Physiology B, 50, $479-484$.

Bunea, R., Farrah, K.E., \& Deutsch, L. (2004). Evaluation of the Effects of Neptune Krill Oil on the Clinical Course of Hyperlipidemia. Alternative Medicine Review, 9, 420428.

Calder, P.C. (2006). n-3 Polyunsaturated fatty acids, inflammation, and inflammatory diseases. The American Journal of Clinical Nutrition, 83 (suppl), 1505S-1019S. 
Carnielli, V.P., Verlato, G., Pederzini, F., Luijendijk, I., Boerlage, A., Pedrotti, D.,\& Sauer, P.J. (1998). Intestinal absorption of long-chain polyunsaturated fatty acids in preterm infants fed breast milk or formula. The American Journal of Clinical Nutrition, 67, 97-103.

Chen, Y., \& Jaczynski, J. (2007). Protein Recovery from Rainbow Trout (Oncorhynchus mykiss) Processing Byproducts via Isoelectric Solubilization/Precipitation and Its Gelation Properties as Affected by Functional Additives. Journal of Agriculture and Food Chemistry, 55, 9079-9088.

Deuchi, K., Kanauchi, O., Imasato, Y., \& Kobayashi, E. (1994). Decreasing Effect of Chitosan on the Apparent Fat Digestibility by Rats Fed on a High-fat Diet. Biosciences, Biotechnology, and Biochemistry, 58,1617-1620.

Düsing, R., Struck, A., Göbel, B., Weisser, B., \& Vetter, H. (1990). Effects of n-3 fatty acids on renal function and renal prostaglandin E metabolism. Kidney International, $38,315-319$.

Emken , E.A., Adolf, R.O., Duval, S.M., \& Nelson, G.J. (1999). Effect of Dietary Docosahexaenoic Acid on Desaturation and Uptake in vivo of Isotope-Labeled Oleic, Linoleic, and Linolenic Acids by Male Subjects. Lipids, 34, 785-791.

Engström, K., Luostarinen, R., \& Saldeen, T. (1996). Whole blood production of thromboxane, prostacyclin and leukotriene $\mathrm{B}_{4}$ after dietary fish oil supplementation in man: effect of vitamin E. Prostaglandins, Leukotrienes and Essential Fatty Acids, 54, $419-425$. 
Fritsche, K. L. \& Johnston, P. V. (1990). Effect of Dietary $\alpha$-Linolenic Acid on Growth, Metastasis, Fatty Acid Profile and Prostaglandin Production of Two Murine Mammary Adenocarcinomas. Proceedings of the Society for Experimental Biology and Medicine, 189, 52-60.

Froyland, L., Vaagenes, H., Asiedu, D.K., Garras, A., Lie, O., \& Berge, R.K. (1996). Chronic administration of eicosapentaenoic acid and docosahexaenoic acid as ethyl esters reduced plasma cholesterol and changed the fatty acid composition in rat blood and organs. Lipids, 31, 169-178.

Gigliotti, J., Jacyzynski, J., \& Tou, J.C. (2008). Determination of the Nutritional Value, Protein Quality and Safety of Krill Protein Concentrate Isolated Using an Isoelectric Solubilization/Precipitation Technique. Journal of Food Chemistry, 111, 209-214.

Grimsgaard, S., Bonaa, K.H., Hansen, J.B., \& Nordøy, A. (1997). Highly purified eicosapentaenoic acid and docosahexaenoic acid in humans have similar triacylglycerol-lowering effects but divergent effects on serum fatty acids. The American Journal of Clinical Nutrition, 66, 649-59.

Gropper, S.S., Smith, J.L., \& Groff, J.L. (2005). Advanced nutrition and human metabolism, 4th ed. Thomson-Wadsworth, CA.

Halliwell, B. (1996). Oxidative stress, nutrition, and health. Experimental strategies for optimization of nutritional antioxidant intake in humans. Free Radical Research, 25, 57-74.

Horrocks, L.A. \& Yeo, Y.K. (1999). Health Benefits of Docosahexaneoic Acid (DHA). Pharmacological Research, 40, 211-225. 
Innis, S.M, Rioux, F.M., Auestad, N., \& Ackman, R.G. (1995). Marine and Freshwater Fish Oil Varying in Arachidonic, Eicosapentaenoic and Docosahexaenoic Acids Differ in their Effects on Organ Lipids and Fatty Acids in Growing Rats. The Journal of Nutrition, 125, 2286-2293

Innis, S.M. (2007). Dietary (n-3) fatty acids and brain development. The Journal of Nutrition, 137, 855-859.

Jacques, H., Gascon, A., Bergeron, N., Lavigne, C., Hurley, C., Deshaies, Y., Moorjani, S., \& Julien, P. (1995). Role of dietary fish protein in the regulation of plasma lipids. Canadian Journal of Cardiology, 11, 63G-71G.

Kelley, D.S., Taylor, P.C., Nelson, G.J., Schmidt, P.C., Ferretti, A., Erickson, K.L., Yu, R., Chandra, R.K., \& Mackey, B.E. (1999). Docosahexaenoic Acid Ingestion Inhibits Natural Killer Cell Activity and Production of Inflammatory Mediators in Young Healthy Men. Lipids, 34, 317-324.

Kolakowska, A., Kolakowska, E., \& Szcygielski, M. (1994). Winter season krill (Euphausia superba Dana) as a source of n-3 polyunsaturated fatty acids. Die Nahrung, 38, 128-134.

Kris-Etherton, P.M., Harris, W., \& Appel, L.J. (2002). Fish Consumption, Fish Oil, Omega-3-Fatty Acids, and Cardiovascular Disease. Journal of the American Heart Association, 106, 2747-2757.

Leigh-Firbank, E.C., Minihane, A.M., Leake, D.S., Wright, J.W., Murphy, M.C., Griffin, B.A., \& Williams, C.M. (2002). Eicosapentaneoic acid and docosahexaneoic acid 
from fish oils: differential associations with lipid responses. British Journal of Nutrition, 87, 435-445.

Mathews, S.A., Oliver, W.T., Phillips, O.T., Odle, J., Diersen-Schade, D.A., \& Harrell, R.J. (2002). Comparison of Triglycerides and Phospholipids as Supplemental Sources of Dietary Long-Chain Polyunsaturated Fatty Acids in Piglets. The Journal of Nutrition, 132, 3081-3089.

Mori, T.A., Burke, V., Puddey, I.B., Watts, G.F., O’Neal, D.N., Best, J.D., \& Beilin, L.J. (2000). Purified eicosapentaenoic and docosahexaneoic acids have differential effects on serum lipids and lipoproteins, LDL particle size, glucose, and insulin in mildly hyperlipidemic men. The American Journal of Clinical Nutrition, 71, 1085-1094.

Murphy, M.G., Wright, V., Ackman, R.G., \& Horackova, M. (1997). Diets enriched in menhaden fish oil, seal oil, or shark liver oil have distinct effects on the lipid and fatty-acid composition of guinea pig heart. Molecular and Cellular Biochemistry, $177,257-269$.

Nicol, S., James, A., \& Pitcher, G. (1987). A first record of daytime surface swarming by Euphausia lucens in the Southern Benguela region. Marine Biology, 94, 7-10.

Nishioka, T., Havinga, R., Tazuma, S., Stellaard, F., Kuipers, F., \& Verkade, H.J. (2004). Administration of phosphatidylcholine-cholesterol liposomes partially reconstitutes fat absorption in chronically bile-divertedrats. Biochimica et Biophyisica Acta, 1636, 90-98.

Park, Y. \& Harris, H. (2002). EPA, but not DHA, decreases mean platelet volume in normal subjects. Lipids, 37, 941-946. 
Phleger, C.F., Nelson, M.M., Mooney, B.D., \& Nichols, P.D. (2002). Interannual and between species comparison of the lipids, fatty acids and sterols of Antarctic krill from the US AMLR Elephant Island survey area. Comparative Biochemistry and Physiology Part B: Biochemistry and Molecular Biology, 132, 819-820.

Porter, N.A., Caldwell, S.E., \& Mills, K.A. (1995). Mechanisms of free radical oxidation of unsaturated lipids. Lipids, 30, 277-290.

Rambjor, G.S., Walen, A.I., Windsor, S.L., \& Harris, W.S. (1996). Eicosapentaenoic Acid Is Primarily Responsible for Hypotriglyceridemic Effect of Fish Oil in Humans. Lipids, 31, S45-S49.

Saito, M. \& Kubo, K. (2002). An assessment of docosahexaneioc acid intake from the viewpoint of safety and physiological efficacy in matured rats. Annals of Nutrition and Metabolism, 46, 176-181.

Song, J.H. \& Miyazawa, T., (2001). Enhanced level of n-3 fatty acid in membrane phospholipids induces lipid peroxidation in rats fed dietary docosahexaenoic acid oil. Atherosclerosis, 155, 9-18.

Valenzuela, A., Nieto, S., Sanhueza, J., Nuñez, M.J., \& Ferrer, C. (2005). Tissue Accretion and Milk Content of Docosahexaenoic Acid in Female Rats after Supplementation with Different Docosahexaenoic Acid Sources. Annals of Nutrition \& Metabolism, 49, 325-332.

Wergedahl, H., Gudbrandsen, O.A., Rost, T.H., \& Berge, R.K. (2009). Combination of fish oil and fish protein hydrolysate reduces plasma cholesterol level in high-fat-fed Wistar rats. Nutrition, 25, 98-104. 
Werner, A., Havinga, R., Kuipers, F., \& Verkade, H.J. (2004). Treatment of EFA deficiency with dietary triglycerides or phospholipids in a murine model of extrahepatic cholestasis. AJP-Gastrointestinal and Liver Physiology, 286, G822G832.

Wong, S., Fisher, E.A., and Marsh, J.B. (1989). Effects of Eicosapentaenoic and Docosahexaenoic Acids on Apoprotein B mRNA and Secretion of Very Low Density Lipoprotein in HepG2 Cells. Arteriosclerosis, 9, 836-841.

Woodman, R.J., Mori, T.A., Burke, V., Puddey, I.B., Watts, G.F., \& Beilin, L.J. (2002). Effects of purified eicosapentaenoic and docosahexaenoic acids on glycemic control, blood pressure, and serum lipids in type 2 diabetic patients with treated hypertension. The American Journal of Clinical Nutrition, 76, 1007-1015. 
Table 1. Diet Composition ${ }^{\text {a }}$ (Gigliotti et al., 2008)

\begin{tabular}{lcc}
\hline \multicolumn{1}{c}{ Ingredients (g/kg diet) } & $\mathbf{C O}^{\mathbf{b}}$ & $\mathbf{K O}+\mathbf{C O}^{\mathbf{b}}$ \\
\hline Casein & 115 & 0 \\
DL-Methionine & 1.5 & 0 \\
Sucrose & 531.8 & 609.8 \\
Corn Starch & 200 & 229.4 \\
Corn Oil & 53.5 & 49.9 \\
Cellulose & 52 & 59.6 \\
Vitamin Mix & \\
Ethoxyquin & 10 & 11.5 \\
Mineral Mix & 0.01 & 0.01 \\
Calcium Phosphate & 13.4 & 15.3 \\
Calcium Carbonate & 20.2 & 20.9 \\
\hline
\end{tabular}

${ }^{a}$ Based on the AIN-93G diet vitamin and mineral mixes (Reeves et al., 1993).

${ }^{b}$ Diet formulated for $872 \mathrm{~g}$ of diet $+128 \mathrm{~g}$ addition of KPC

$\mathrm{KPC}=$ Krill Protein Concentrate 
Table 2. Fatty Acid Composition of Dietary Oils

\begin{tabular}{|c|c|c|}
\hline Fatty acid & $\mathrm{KO}+\mathrm{CO}^{1}$ & $\mathrm{CO}^{1}$ \\
\hline 18:2 ( $\omega-6)$, LA & 2.61 & 3.11 \\
\hline 18:3 ( $\omega-3)$, ALA & 0.05 & 0.05 \\
\hline $20: 4(\omega-6)$, AA & 0.01 & -- \\
\hline $20: 5(\omega-3)$, EPA & 0.11 & -- \\
\hline 22:6 ( $\omega-3)$, DHA & 0.11 & -- \\
\hline$\omega-6: \omega-3$ & $10: 1$ & $62: 1$ \\
\hline
\end{tabular}

${ }^{1}$ Results are given as $\mathrm{mg} / \mathrm{g}$ diet 
Table 3. Apparent Digestibility ${ }^{\mathrm{a}}$

\begin{tabular}{|c|c|c|c|c|c|c|}
\hline \multirow[b]{2}{*}{ Fatty Acid } & \multicolumn{2}{|c|}{ Intake (mg) } & \multicolumn{2}{|c|}{ Fecal Excretion (mg) } & \multicolumn{2}{|c|}{ Apparent Digestibility (\%) } \\
\hline & $\mathrm{KO}+\mathrm{CO}$ & $\mathrm{CO}$ & $\mathrm{KO}+\mathrm{CO}$ & $\mathrm{CO}$ & $\mathrm{KO}+\mathrm{CO}$ & $\mathrm{CO}$ \\
\hline LA $(18: 2 \omega-6)$ & $303.13 \pm 6.17^{*}$ & $346.50 \pm 13.79$ & $17.34 \pm 3.66$ & $10.68 \pm 2.54$ & $93.76 \pm 1.06^{*}$ & $96.93 \pm 1.06$ \\
\hline $\operatorname{ALA}(18: 3 \omega-3)$ & $6.32 \pm 0.13^{*}$ & $5.49 \pm 0.22$ & $2.88 \pm 0.65$ & $2.07 \pm 0.41$ & $49.02 \pm 10.58$ & $62.86 \pm 6.26$ \\
\hline AA $(20: 4 \omega-6)$ & $1.27 \pm 0.03 *$ & -- & $0.97 \pm 0.20^{*}$ & -- & $22.75 \pm 6.45^{*}$ & -- \\
\hline $\operatorname{EPA}(20: 5 \omega-3)$ & $13.28 \pm 0.27 *$ & -- & $3.6 \pm 0.57$ & -- & $70.12 \pm 3.52 *$ & -- \\
\hline DHA $(22: 6 \omega-3)$ & $12.89 \pm 0.29^{*}$ & -- & $0.77 \pm 0.21$ & -- & $93.42 \pm 1.64 *$ & -- \\
\hline Total lipids (g) & $6.16 \pm 0.13$ & $5.91 \pm 0.24$ & $0.78 \pm 0.11$ & $0.76 \pm 0.10$ & $86.10 \pm 1.36$ & $87.17 \pm 1.36$ \\
\hline
\end{tabular}

${ }^{a}$ Values are given as mean $\pm \mathrm{SEM}$

* Indicates significant difference at $P<0.05$ by the Student's $t$-test

$\mathrm{LA}=$ linolenic acid, ALA $=\alpha$-linolenic acid, $\mathrm{AA}=$ arachidonic acid, EPA $=$ eicosapentaenoic acid, DHA $=$ Docosahexaenoic acid 
Table 4. Fatty Acid Analysis of Tissues ${ }^{\text {a }}$

\begin{tabular}{|c|c|c|c|c|c|c|c|c|}
\hline & \multicolumn{2}{|c|}{ Brain } & \multicolumn{2}{|c|}{ Gonadal Fat Pad } & \multicolumn{2}{|c|}{ Retroperitoneal Fat Pad } & \multicolumn{2}{|c|}{ Liver } \\
\hline $\begin{array}{l}\text { Fatty Acid } \\
\text { (mg/g tissue) }\end{array}$ & $\mathrm{KO}+\mathrm{CO}$ & $\mathrm{CO}$ & $\mathrm{KO}+\mathrm{CO}$ & $\mathrm{CO}$ & $\mathrm{KO}+\mathrm{CO}$ & $\mathrm{CO}$ & $\mathrm{KO}+\mathrm{CO}$ & $\mathrm{CO}$ \\
\hline LA $(18: 2 \omega-6)$ & $0.20 \pm 0.06$ & $0.08 \pm 0.041$ & $58.06 \pm 6.25$ & $60.79 \pm 3.74$ & $38.25 \pm 3.25$ & $43.51 \pm 4.12$ & $3.38 \pm 0.29$ & $3.24 \pm 0.25$ \\
\hline $\operatorname{ALA}(18: 3 \omega-3)$ & $0.15 \pm 0.06$ & $0.21 \pm 0.07$ & $1.54 \pm 0.15$ & $1.67 \pm 0.13$ & $1.38 \pm 0.12$ & $0.99 \pm 0.15$ & ND & ND \\
\hline AA $(20: 4 \omega-6)$ & $1.99 \pm 0.16$ & $2.09 \pm 0.28$ & $0.69 \pm 0.11$ & $1.04 \pm 0.12$ & $0.32 \pm 0.12^{*}$ & $0.90 \pm 0.09$ & $1.94 \pm 0.10^{*}$ & $3.94 \pm 0.15$ \\
\hline $\operatorname{EPA}(20: 5 \omega-3)$ & ND & ND & $0.87 \pm 0.26^{*}$ & ND & $0.74 \pm 0.19^{*}$ & ND & $0.76 \pm 0.04^{*}$ & ND \\
\hline DHA $(22: 6 \omega-3)$ & $2.85 \pm 0.24^{*}$ & $2.46 \pm 0.37$ & $0.92 \pm 0.36^{*}$ & ND & $0.78 \pm 0.19^{*}$ & ND & $1.67 \pm 0.10^{*}$ & $0.72 \pm 0.026$ \\
\hline
\end{tabular}

${ }^{\mathrm{a}}$ Values are given as mean $\pm \mathrm{SEM}$

* Indicates significant difference at $P<0.05$ by the Student's $t$-test

$\mathrm{ND}=$ not detectable, $\mathrm{LA}=$ linolenic acid, $\mathrm{ALA}=\alpha$-linolenic acid, $\mathrm{AA}=$ arachidonic acid, $\mathrm{EPA}=$ eicosapentaenoic acid, $\mathrm{DHA}=$

Docosahexaenoic acid. 
Table 5. Oxidants and Antioxidants ${ }^{\mathrm{a}}$

\begin{tabular}{ccc}
\hline & KO $+\mathbf{C O}$ & $\mathbf{C}+\mathbf{C O}$ \\
\hline \hline Antioxidant Capacity (mM trolox) & & \\
Baseline Urine & $3.58 \pm 0.71$ & $5.09 \pm 0.62$ \\
Final Urine & $5.15 \pm 0.57$ & $5.73 \pm 1.15$ \\
TBARS (uM MDA) & & \\
Baseline Urine & $26.9 \pm 4.9$ & $29.8 \pm 6.7$ \\
Final Urine & $8.4 \pm 2.1$ & $15.4 \pm 4.5$ \\
Retroperitoneal Fat Pad & $2.30 \pm 0.21$ & $2.20 \pm 0.23$ \\
Gonadal Fat Pad & $1.14 \pm 0.25^{*}$ & $2.00 \pm 0.15$ \\
Liver & $13.40 \pm 0.48$ & $13.07 \pm 0.76$ \\
Brain & $5.57 \pm 0.28$ & $5.93 \pm 0.38$ \\
\hline
\end{tabular}

${ }^{\text {a }}$ Values are given as mean $\pm \mathrm{SEM}$

* Indicates significant difference at $P<0.05$ by the Student's $t$-test 
Figure 2. Effect of diets on $\mathrm{PGE}_{2}$ metabolites ${ }^{\mathrm{a}}$

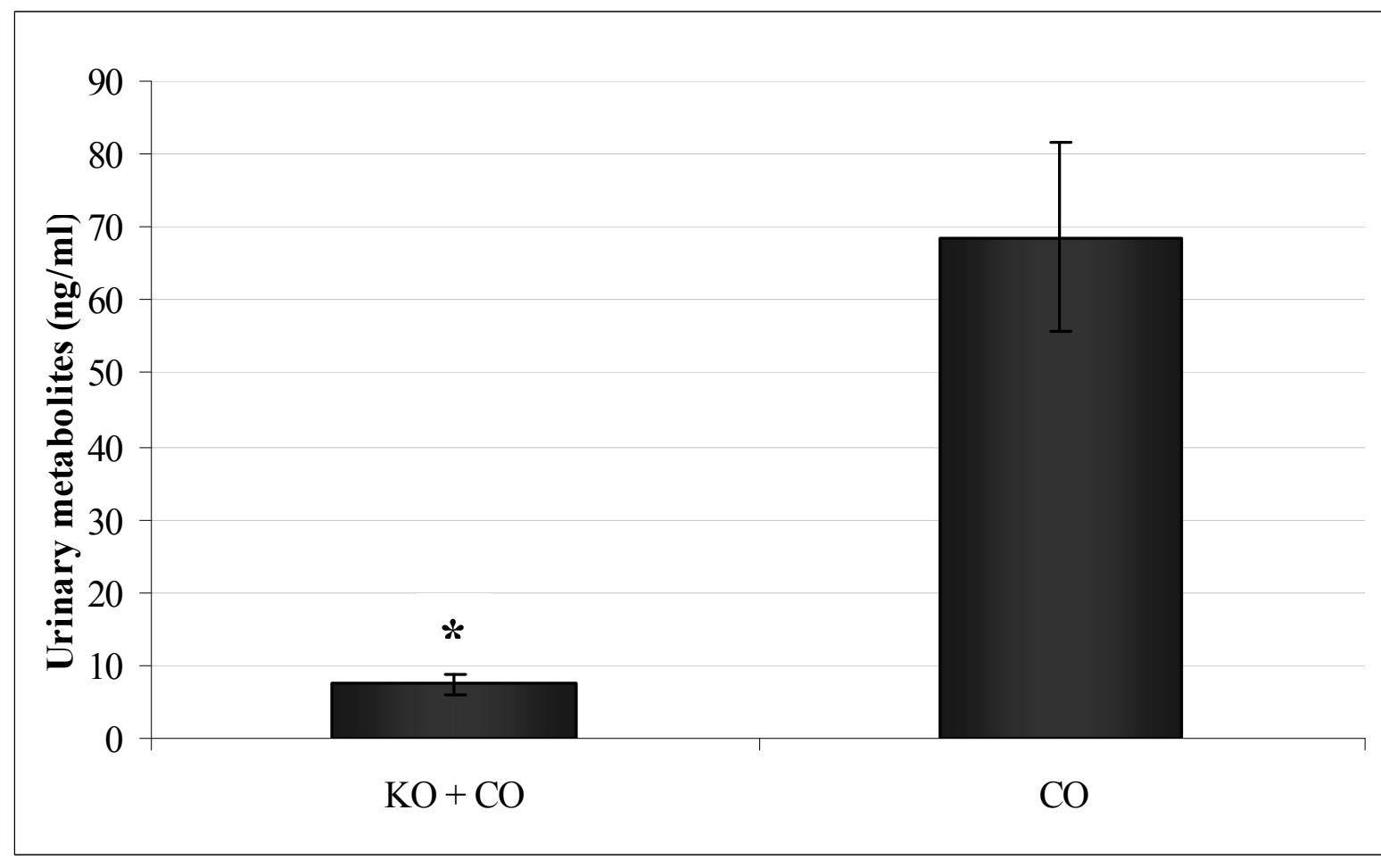

${ }^{a}$ Values are given as mean \pm SEM

* Indicates significant difference at $P<0.05$ by the Student's $t$-test 
Figure 3. Effect of diets on 11-dehydro $\mathrm{TXB}_{2}{ }^{\mathrm{a}}$

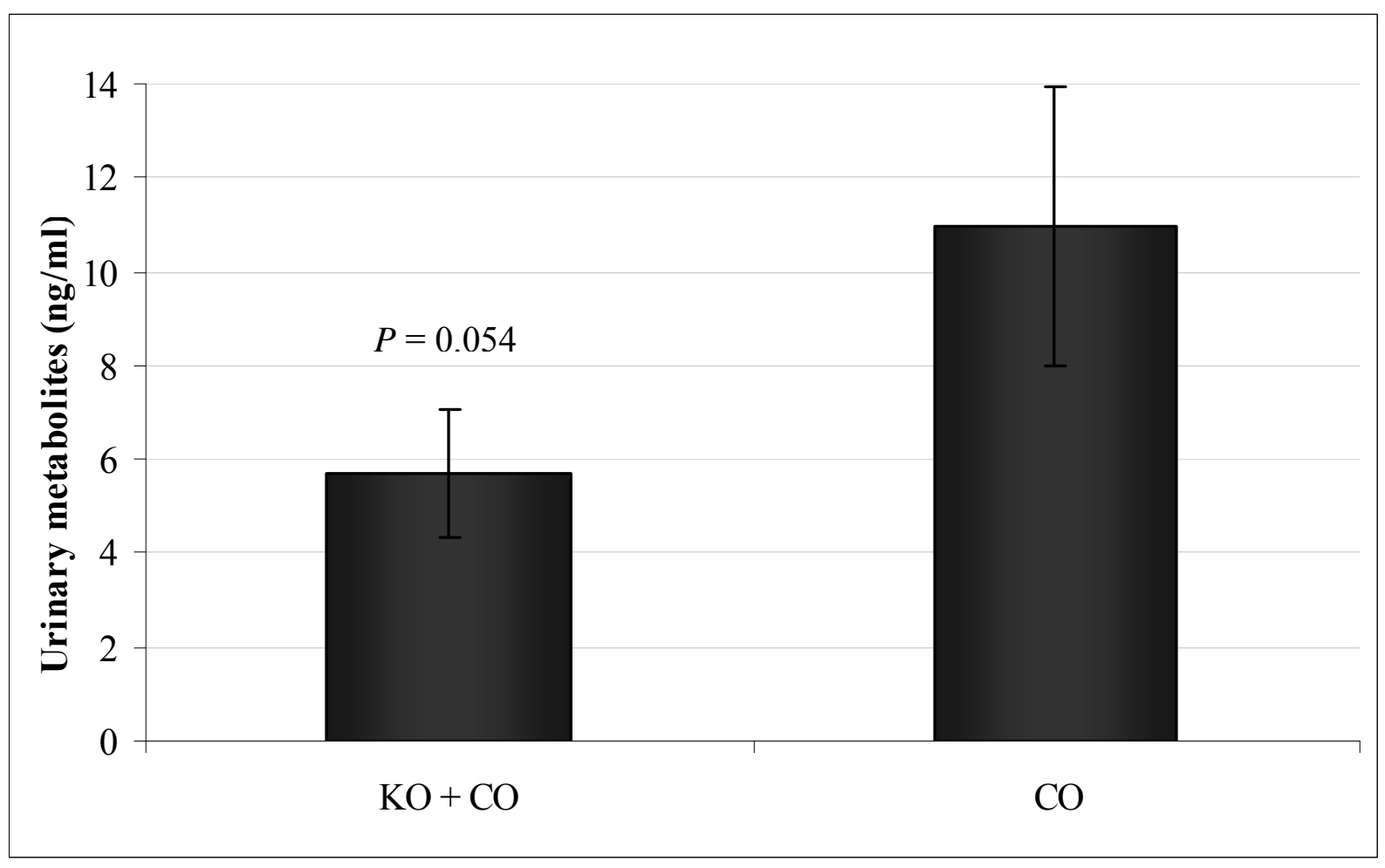

${ }^{\text {a }}$ Values are given as mean $\pm \mathrm{SEM}$ 